\title{
Safety Checklists in the Operating Room
}

\author{
Alexandra Busemann, Claus-Dieter Heidecke
}

\begin{abstract}
Editorial to accompany the article "The effect of the WHO Surgical Safety Checklist on complication rates and interdisciplinary communication" by Fudickar et al. in this issue of Deutsches

Ärzteblatt International
\end{abstract}

Department of General, Visceral Thoracic and Vascular Surgery, Universitätsmedizin Greifswald: Dr. med. Busemann Prof. Dr. med. Heidecke*

${ }^{*}$ Chairman of the Working Group for Quality and Safety in Surgery (CAQS) of the German Society of Surgery
( ver the past decade, increasing attention has been paid to quality and risk management in medicine. Haynes et al., in a path-breaking study published in the New England Journal of Medicine in 2009, showed that the use of a checklist developed by the World Health Organization (WHO) to prevent errors during surgical procedures significantly lowers surgical morbidity and mortality (1). This finding has led surgical societies in Germany and abroad to recommend that the WHO surgical safety checklist be used in all operative procedures. The number of hospitals in Germany that have implemented it to date is not documented.

The WHO website lists only hospitals that have actively registered themselves and thus surely underrepresents the number in which the checklist is now being used (2). In this issue of Deutsches Ärzteblatt International, Fudickar et al. (3) comprehensively review the current literature on "the effect of the WHO surgical safety checklist on complication rates and interdisciplinary communication." In particular, they describe the resulting changes in operatingroom safety culture. The authors' encouraging findings ought to motivate the universal adoption of this new, beneficial instrument.

\section{Checklists should be individually tailored}

The WHO checklist consists of three columns, which correspond to the three phases of an operation: prior to the induction of anesthesia, prior to skin incision, and at the end of the operation. The purpose of all items on the checklist is to prevent certain types of error- "common killers" - that tend to be committed in each of these three periods. The checklist cannot be exhaustive, and the WHO explicitly recommends adapting it to local conditions wherever it is used. Even locally adapted checklists are no more than works in progress: They must be continually readapted, not just used indefinitely without change. As a well-adapted checklist does not come about by chance, rules have been proposed for creating suitable variations of the WHO checklist (4).

If the WHO list were to be used as is, it might be an inadequate safeguard against common perioperative errors, particularly because today's surgical working environment is modular. Patients undergoing minor or moderate surgery are often not cared for by the same physician throughout: The anesthesiologist making the pre-anesthesia visit may not be the one who will give the anesthesia, and the surgeon informing the patient about the operation and obtaining written consent for it may not be the one who will perform it. The risk to the patient rises firstly due to the potential of wrong patient or wrong site surgery and secondly because important information can be transmitted erroneously or simply lost.

These processes would clearly be better if the surgeon who will actually perform the operation sees the patient personally beforehand and confirms the indication for surgery (even if this surgeon is not necessarily the one who obtains the patient's informed consent). This is, at least, the view of the Working Group for Quality and Safety in Surgery, a committee of the German Society of Surgery (DGCh). We therefore propose that future checklists should take account of the potentially problematic information transfer from one physician to another, perhaps by including one or more additional columns for surgical safety. Admittedly, organizational problems could easily arise, as when a patient is admitted to the hospital by a surgeon on weekend call who will no longer be on duty later on in the week when the operation is to be performed.

\section{Introducing a preoperative column}

The Dutch working group of deVries, Boermeester, and colleagues has created the SURPASS checklist to reflect the entire process of surgical treatment, not just what happens in the operating room (5); its use was found to lower peri- and postoperative morbidity significantly. Because highly complex checklists of this kind are very cumbersome to implement, there can be no expectation of their universal use in Germany any time soon. A promising modified approach for bridging the safety gap would be to introduce a preoperative column into the checklist (6).

The authors describe the successful implementation of such a checklist at the University Medical Center Schleswig-Holstein (Campus Kiel), initially in a single surgical department (oral and maxillofacial surgery). Similarly, at the Greifswald University Medical Center, the surgical checklist was first used in the general surgery department, where it was systematically adapted on the basis of on-site experience, an audit, and staff acceptance. Our experience suggests that a number of features of the original 
checklist need to be adapted to local conditions in Germany. In this country, for example, respiratory function is monitored with pulse oximetry in practically all interventional and surgical procedures. Because the monitoring of oxygen saturation is now automatic, it is less susceptible to error and would not seem to require inclusion in the checklist. On the other hand, our team strongly believes that just marking the side or location where the procedure is to be performed is an inadequate safeguard against performance of the operation in the wrong place (6). We typically mark the intended incision itself, or the trochar insertion site(s); This has the added benefit of being a form of communication with the patient, integrating him or her more fully into the treatment process and providing an opportunity to ask questions in case of uncertainty.

The literature provides no guidance yet on how to improve compliance with the checklist (i.e., completeness of processing), which tends to be suboptimal when the checklist is first introduced (as has been pointed out by [7] and confirmed by our personal experience). The Kiel team now uses a "checklist coordinator" for the "team time-out." Later, when more experience has been gained, all operative personnel will be required to perform the "time-out," which will, in time, become second nature to all concerned; the coordinator will then be superfluous. Acceptance of the checklist in all surgical specialties depends crucially on communication across specialties, as well as among the different professions that constitute the personnel of an operating room (8).

\section{The idea of structuring treatment with clinical pathways}

Have we already successfully met the goal of error prevention? The authors discuss the introduction of sequentially applied checklists for the various different processes (modules) involved in perioperative medicine. A well-known proponent of this is Atul Gawande, author of The Checklist Manifesto (9), who argues that, in the highly complex world of today's medicine, the risks of each diagnostic and therapeutic segment must be addressed systematically. His team has proposed a more extensive packet of checklists for crisis situations that can arise during surgery (10). This way of grouping measures and procedures together corresponds to the idea of structuring treatment with clinical pathways (11). The circle will close with fully process-oriented structuring of hospitalizations for surgical treatment: Structure and processes account for clinical outcomes, and clinical risk management constitutes a basic component of quality management.

\section{Conflict of interest statement}

Prof. Heidecke has received payment from Johnson \& Johnson and from the Aesculap-Akademie for the preparation of scientific continuing education presentations.

Dr. Busemann states that no conflict of interest exists.

Translated from the original German by Ethan Taub, M.D.

\section{REFERENCES}

1. Haynes AB, Weiser TG, Berry WR, et. al.: Safe Surgery Saves Lives Study Group: A surgical safety checklist to reduce morbidity and mortality in a global population. N Engl J Med 2009; 360: 491-9.

2. Surgical Safety Web Map: http://maps.cga.harvard.edu: 8080/Hospital/\# (last accessed on 7 July 2012)

3. Fudickar A, Hörle K, Wiltfang J, Bein B: Auswirkungen der Surgical Safety Checklist der WHO auf Komplikationsrate und interdisziplinäre Kommunikation. Dtsch Arztebl Int 2012; 109(42): 695-701

4. Weiser TG, Haynes AB, Lashoher A, et al.: Perspectives in quality: designing the WHO Surgical Safety Checklist. Int J Qual Health Care 2010; 22: 365-70.

5. de Vries EN, Prins HA, Crolla RM, et al.: Effect of a comprehensive surgical safety system on patient outcomes. N Engl J Med 2010; 363: 1928-37.

6. Busemann A, Schreiber A, Heidecke CD: Einführung von Operationschecklisten als Teil des Risikomanagements. Sind harte Daten zur Komplikationsvermeidung verfügbar? Chirurg 2012; 83: 611-6

7. Levy SM, Senter CE, Hawkins RB, et al.: Implementing a surgical checklist: More than checking a box. Surgery 2012; Jul 6 [Epub ahead of print].

8. Walker IA, Reshamwalla S, Wilson $\mathrm{H}$ : Surgical safety checklists: do they improve outcomes? Br J Anaesth 2012; 109: 47-54

9. Gawande AA: The checklist manifesto - how to get things right. New York: Picador-Verlag, 2009

10. Ziewacz JE, Arriaga AF, Bader AM, et al.: Crisis checklists for the operating room: development and pilot testing. J Am Coll Surg 2011; 213: 212-7

11. Schwarzbach M, Ronellenfitsch U: Klinikpfade in der Chirurgie ein Instrument für den Routinebetrieb? Dtsch Arztebl 2008; 105(47): A 2512-6.

\section{Corresponding author}

Prof. Dr. med. Claus-Dieter Heidecke, MBA

Klinik für Chirurgie,

Abteilung für Allgemeine Chirurgie,

Viszeral-, Thorax- und Gefäßchirurgie

Ferdinand-Sauerbruch-Str.

17475 Greifswald, Germany

heidecke@uni-greifswald.de

\section{Cite this as:}

Busemann A, Heidecke CD: Safety checklists in the operating room. Dtsch Arztebl Int 2012; 109(42): 693-4. DOI: 10.3238/arztebl.2012.0693 